Article

\title{
Effect of Co-Use of Fly Ash and Granular Polyacrylamide on Infiltration, Runoff, and Sediment Yield from Sandy Soil under Simulated Rainfall
}

\author{
Kai Yang ${ }^{1, * \mathbb{D}}$, Zejun Tang ${ }^{2}$ and Jianzhang Feng ${ }^{2}$ \\ 1 Laboratory for Earth Surface Processes, College of Urban and Environmental Sciences, Peking University, \\ Beijing 100871, China \\ 2 College of Water Resources and Civil Engineering, China Agricultural University, Beijing 100083, China; \\ tangzejun@sina.com (Z.T.); fjz063@163.com (J.F.) \\ * Correspondence: yangkai@pku.edu.cn; Tel.: +86-138-1175-3081
}

Received: 1 February 2020; Accepted: 28 February 2020; Published: 3 March 2020

\begin{abstract}
Coal fly ash (FA) and polyacrylamide (PAM) are two common amendments for improving hydraulic properties of sandy soil. However, their interaction effect on infiltration-runoff processes in sandy soil has been scarcely reported. In this study, FA and anionic PAM granules were mixed thoroughly with a $0-0.2 \mathrm{~m}$ sandy soil layer at FA rates of $0 \%, 10 \%$, and $15 \%(w / w$ soil), and PAM rates of $0 \%, 0.01 \%$, and $0.02 \%(w / w$ soil) along with each FA rate. A simulated rainfall laboratory experiment (slope gradient of $10^{\circ}$, rainfall intensity of $1.5 \mathrm{~mm} / \mathrm{min}$ ) was conducted. During the rainfall, the cumulative runoff yield increased while the average infiltration rate decreased with increasing FA and PAM rates. A higher FA rate of $15 \%$ and varying PAM rates resulted in a prominent increase in cumulative sediment yield. After the rainfall, the two-dimensional distribution of water content retained in the soil profile reflected that both FA and PAM increased the water retention capacity of sandy soil, and the effect became more obvious at higher FA and PAM rates. The possible mechanism for the effect of FA and PAM on inhibiting water infiltration during the rainfall and retaining water in the soil layer after the rainfall is attributed to the filling of pores of the coarse soil particles by fine-sized FA particles and flocculation function and binding action of PAM.
\end{abstract}

Keywords: runoff; sediment; erosion; infiltration; amendment

\section{Introduction}

Sandy soils represent one group of problem soils. They are coarse-textured and have high hydraulic conductivities and low water holding capacity. Consequently, sandy soils are prone to water drainage, which reduces the water and nutrient use efficiency of plants grown in the soil. Therefore, strategies are required to improve water storage in sandy soils.

Among common ameliorants for improving coarse-textured soils, coal fly ash (FA) which predominates in the solid residue generated from coal combustion, has been extensively reported to be effective in retaining water in the amended sandy soil [1-8]. The underlying mechanism of improved water holding capacity of sandy soil by FA is due to change of soil texture by fine-sized FA particles [4-6]. In addition, water-soluble, high molecular weight, anionic polyacrylamide (PAM) have been widely used as a soil conditioner for soil and water conservation [9-22]. PAM can stabilize soil via binding particles together in a soil aggregate and reducing repulsive force among soil particles $[11,13]$. In addition to the sole land application of either FA or PAM, a couple of researches have been conducted to increase the effectiveness of these two soil ameliorants by co-application with other amendments. Co-application of FA with inorganic materials (e.g., lime, gypsum, red mud, zeolite, steel 
slag) and organic materials (e.g., composts, farmyard manure, sewage sludge, press mud, paper waste, biofertilizer, biochar) has been demonstrated to enhance the efficiency of amendment, with advantages such as enhancing nutrient availability, reducing potential toxic element availability, buffering soil $\mathrm{pH}$, increasing soil organic matter content, and stimulating microbial activity [23-25]. PAM has been mixed with phosphogypsum as a source of electrolytes to achieve a more effective reduction in runoff and erosion in soils $[15,26,27]$.

Based on the specific properties of FA and PAM, one can therefore expect that interaction between FA and PAM may produce a synergistic effect on improving sandy soil quality. Nevertheless, there have been very limited studies reporting co-application of FA and PAM in sandy soils. Previously, we demonstrated that co-utilization of FA and PAM as a sand-fixing agent could improve the structural stability of sandy soil and its antiwind erosion ability [28-30]. However, the interaction effect of FA and PAM on water migration in sandy soil especially under rainfall conditions has been scarcely reported. The aims of this study were (i) to investigate the relationship between infiltration, runoff, and sediment yield in sandy soil treated with FA and PAM under simulated rainfall, and (ii) to characterize the redistribution of water retained in the soil layer after the rainfall.

\section{Materials and Methods}

\subsection{Experimental Soil, FA, and PAM}

The experimental soil was collected from the surface soil $(0-0.2 \mathrm{~m})$ at the Wantong Modern Agriculture \& Animal Husbandry Technology Park in Ordos City, Inner Mongolia Autonomous Region, China. The soil sample represents the poor soil spreading across Inner Mongolian Reach of the Yellow River. The climate in this region is featured by low and greatly varying rainfall and frequent dust storms. The annual rainfall is in the range of $150-400 \mathrm{~mm}$, with most of the rainfall occurring in July, August and September, and predominated by intense rainfalls [31]. The soil was air-dried and passed through a 2-mm stainless steel sieve to remove plant roots and other extraneous materials. The particle size distribution was determined by the laser diffraction method (ISO 13320:2009) using a particle size analyzer (Mastersizer 2000, Malvern Instruments, Malvern, UK). The soil was classified as a very alkaline sandy soil $(\mathrm{pH} 8.90)$, with a sand $(20-2000 \mu \mathrm{m})$ content of $88.6 \%(v / v)$, silt $(2-20 \mu \mathrm{m})$ content of $9.8 \%(v / v)$, and clay $(0.01-2 \mu \mathrm{m})$ content of $1.6 \%(v / v)$. The sandy soil had a bulk density of $1.49 \mathrm{Mg} / \mathrm{m}^{3}$ and a very low organic matter content of $0.24 \%$.

The high-calcium FA was taken from the FA dry disposal site of the Dalate Thermal Power Plant with a total installed generating capacity of 3.18 million kW in Ordos City. Inner Mongolian Reach of the Yellow River is rich in FA due to many large-scale thermal power plants that operated in this region [32]. A large amount of FA has been disposed of in landfills, not only wasting land resources but also posing a threat to the local environment [32]. The FA was air-dried, gently ground, and 2-mm sieved. The particle size distribution in the FA was predominated by particles in the size range of $2-20 \mu \mathrm{m}$, accounting for $69.6 \%(v / v)$, with $27.7 \%(v / v)$ coarser particles $(20-2000 \mu \mathrm{m})$ and $2.7 \%(v / v)$ finer particles $(0.01-2 \mu \mathrm{m})$. The FA was extremely alkaline ( $\mathrm{pH} 10.8)$. The major potential toxic elements in the FA included $10.91 \mathrm{mg} / \mathrm{kg} \mathrm{As}, 110.68 \mathrm{mg} / \mathrm{kg} \mathrm{Cr}, 50.24 \mathrm{mg} / \mathrm{kg} \mathrm{Cu}, 5.30 \mathrm{mg} / \mathrm{kg} \mathrm{Hg}, 41.57 \mathrm{mg} / \mathrm{kg}$ $\mathrm{Ni}, 27.26 \mathrm{mg} / \mathrm{kg} \mathrm{Pb}$, and $67.38 \mathrm{mg} / \mathrm{kg} \mathrm{Zn}$. All values were below the risk screening values for soil contamination of agricultural land according to the Chinese National Standard GB 15618-2018 [33].

The anionic PAM was purchased from Xilong Scientific Co., Ltd. in Shantou City, Guangdong Province. It was a white powder with a polyacrylamide content of $\geq 85 \%$, molecular weight of $\geq 3$ million, and hydrolysis degree of $30 \%$.

\subsection{Experimental Apparatus}

The experimental apparatus was established in the experimental hall of College of Water Resources and Civil Engineering, China Agricultural University, Beijing. It consisted of hydraulic lifting stainless steel platform and simulated rainfall system (Figure 1). The platform had an experimental space of 
$2(\mathrm{~L}) \times 3(\mathrm{~W}) \times 0.4 \mathrm{~m}(\mathrm{H})$ where soil can be loaded. The slope gradient can be adjusted in the range of $0-30^{\circ}$ by a hydraulic tappet. The experimental area was divided equally into 12 plots by $3 \mathrm{~mm}$ thick polyvinyl chloride (PVC) sheets, with an area of $2(\mathrm{~L}) \times 0.25 \mathrm{~m}(\mathrm{~W})$ for each plot. The central nine plots were used in the experiment. After loading the soil onto each plot, the PVC sheet was left $0.1 \mathrm{~m}$ above the soil surface to eliminate any disturbance between adjacent plots caused by raindrop and sediment splashes. For each plot, a V-shape PVC unit with a plastic bucket was installed at the runoff discharge end to collect runoff. The slope bottom floor had uniformly distributed small holes $(\Phi 3 \mathrm{~mm}$, 2 holes per $\mathrm{cm}^{2}$ ) which allow the air in the soil to vent and therefore eliminate its influence on rainfall infiltration. The simulated rainfall system consisted of a rectangular water supply system, pressure control system, and spray system. There were four sets of sprinklers located at the middle point of each of the four sides (Figure 1). The rainfall system was designed to guarantee a constant rainfall intensity (range $0.5-2 \mathrm{~mm} / \mathrm{min}$ ) and rainfall uniformity.

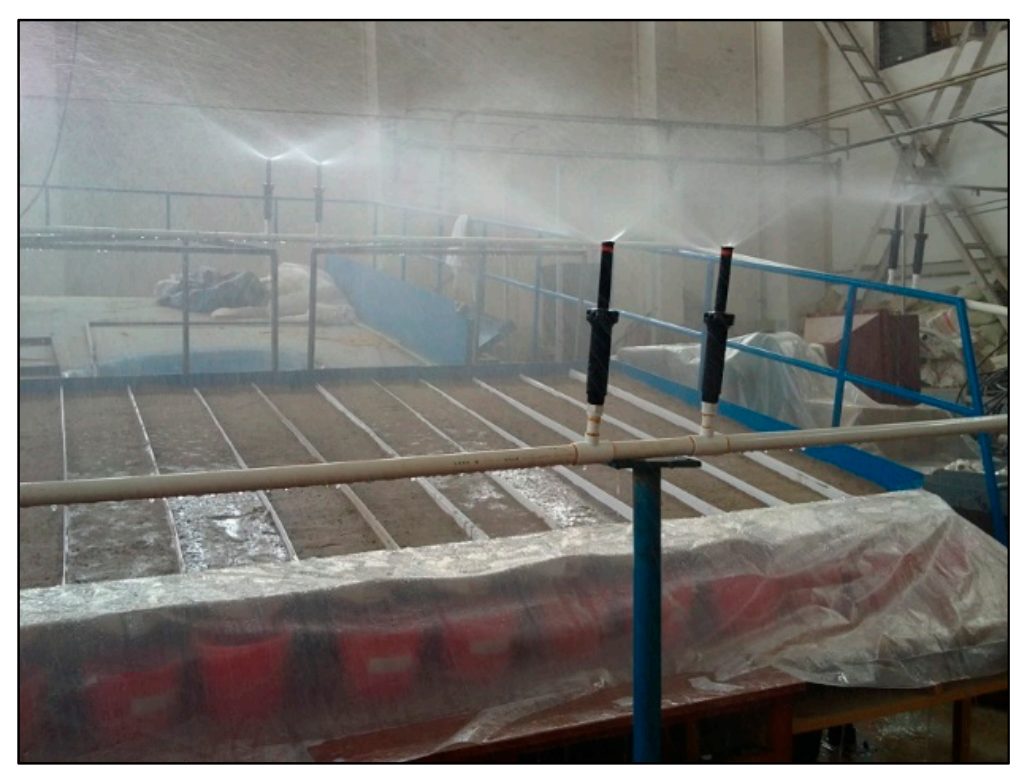

Figure 1. Experimental apparatus for the simulation of sandy slope and rainfall.

\subsection{Experimental Design}

A fixed slope gradient of $10^{\circ}$ and a rainfall intensity of $1.5 \mathrm{~mm} / \mathrm{min}$ were used in this study. Despite that slope gradient in the range of $15-25^{\circ}$ has been commonly used in studies (e.g., Tang et al. [13], Wang et al. [17], Li and Wang [22]) of slope erosion in the Loess Plateau region in western China, taking the relatively flat landform in the selected study area into account, a smaller slope gradient was adopted. The selected rainfall intensity can be regarded within the range of heavy storms. There were three FA rates, viz. $0 \%, 10 \%$, and $15 \%$ ( $w / w$ soil). For each FA rate, there were three PAM rates, viz. $0 \%, 0.01 \%$, and $0.02 \%$ ( $w / w$ soil). The $0 \%$ FA and $0 \%$ PAM treatment (untreated sandy soil) was set as a control group. There was a total of nine treatments. Each treatment was prepared in triplicates. In order to achieve this, the rainfall event was repeated three times. For each rainfall event, there was one replicate of each of the nine treatments. A gravel layer $(0-0.1 \mathrm{~m})$ was placed on the slope bottom floor. Gauze was then placed on the gravel layer surface for the purpose of easy removal of the soil. FA and PAM were mixed uniformly with the soil according to the above application rates. The untreated or treated soil was then loaded onto each plot, layer by layer $(0.025 \mathrm{~m}$ thick per layer) at a bulk density of $1.5 \mathrm{Mg} / \mathrm{m}^{3}$ (similar to that of the field cultivated layer in the study area) to reach a thickness of $0.2 \mathrm{~m}$. In order to achieve a homogeneous soil layer, each sublayer surface was roughed up prior to loading the next $0.025 \mathrm{~m}$ layer onto it. Finally, all plots were covered with a plastic film and ready for the simulated rainfall experiment. Upon finishing each rainfall trial, all treatments were removed and replaced by a new replicate of each treatment for the next rainfall trial. 
During the rainfall event, when the rainfall intensity reached $1.5 \mathrm{~mm} / \mathrm{min}$, the plastic film was removed immediately. The initial runoff yield time for each plot was recorded. The runoff from each plot was then collected every $5 \mathrm{~min}$ in the plastic buckets placed at the slope foot. Rainfall duration depended on runoff yield in each plot. The runoff duration for all plots was approx. $40 \mathrm{~min}$. At the end of the rainfall event, the runoff samples collected in the plastic buckets were stood to allow the suspended solids to settle. Then, the supernatant was measured by a $1 \mathrm{~L}$ measuring cylinder to calculate instantaneous runoff intensity using the following equation:

$$
r_{i}=\left(\frac{10 V_{i}}{A}\right) / t_{i}
$$

where $r_{i}$ is instantaneous runoff intensity at the $i$ th sampling time $(\mathrm{mm} / \mathrm{min}) ; V_{i}$ is volume of runoff sample collected at the $i$ th sampling time $(\mathrm{mL}) ; A$ is plot area $\left(\mathrm{cm}^{2}\right)$. In this study, $A$ is a constant value of $5000 \mathrm{~cm}^{2}$; and $t_{i}$ is time interval to collect the $i$ th runoff sample (min). In this study, $t_{i}$ is a constant value of $5 \mathrm{~min}$.

According to runoff intensities calculated for different treatments with rainfall duration, cumulative runoff yield was calculated using the following equation:

$$
R=\int_{0}^{T} r(t) d t
$$

where $R$ is cumulative runoff yield during a given rainfall period $(\mathrm{mm}) ; r(t)$ is instantaneous runoff intensity at time $t(\mathrm{~mm} / \mathrm{min})$; and $T$ is rainfall duration ( $\mathrm{min}$ ).

Average infiltration rate was calculated using the following Equation [34]:

$$
i_{a}=(P t \cos \alpha-R) / t
$$

where $i_{a}$ is average infiltration rate during a given rainfall period $(\mathrm{mm} / \mathrm{min}) ; P$ is rainfall intensity $(\mathrm{mm} / \mathrm{min})$. In this study, $P$ is a constant value of $1.5 \mathrm{~mm} / \mathrm{min} ; \alpha$ is slope gradient $\left(^{\circ}\right)$. In this study, $\alpha$ is a constant value of $10^{\circ} ; t$ is rainfall duration ( $\mathrm{min}$ ); and $R$ is cumulative runoff yield during the rainfall period of $t(\mathrm{~mm})$.

The sediment precipitated at the bucket bottom was oven-dried and then weighted to calculate instantaneous sediment yield rate using the following equation:

$$
s_{i}=\left(\frac{W_{i}}{A}\right) / t_{i}
$$

where $s_{i}$ is instantaneous sediment yield rate at the $i$ th sampling time $\left(\mathrm{g} / \mathrm{m}^{2} / \mathrm{min}\right) ; W_{i}$ is dry weight of sediment sample collected at the $i$ th sampling time (g); $A$ is plot area $\left(\mathrm{m}^{2}\right)$. In this study, $A$ is a constant value of $0.5 \mathrm{~m}^{2}$; and $t_{i}$ is time interval to collect the $i$ th sediment sample (min). In this study, $t_{i}$ is a constant value of $5 \mathrm{~min}$.

According to sediment yield rates calculated for different treatments with rainfall duration, cumulative sediment yield was calculated using the following equation:

$$
S=\int_{0}^{T} s(t) d t
$$

where $S$ is cumulative sediment yield during a given rainfall period $\left(\mathrm{kg} / \mathrm{m}^{2}\right) ; s(t)$ is instantaneous sediment yield rate at time $t\left(\mathrm{~kg} / \mathrm{m}^{2} / \mathrm{min}\right)$; and $T$ is rainfall duration (min).

All treatments were stood for $4 \mathrm{~h}$ to equilibrate water distribution in the soil profile upon ending the rainfall event. Then, four sampling locations were positioned along the slope at a fixed distance of $0.4,0.8,1.2$, and $1.6 \mathrm{~m}$ to the slope top. At each sampling location, soil samples were taken at a depth 
of $0-0.04,0.04-0.08,0.08-0.12,0.12-0.16$, and $0.16-0.2 \mathrm{~m}$, and analyzed for soil water content by the oven-dry method.

Data were expressed as mean value of triplicates. The differences between treatments were analyzed using one-way analysis of variance (ANOVA), and the means were compared by the least significant difference (LSD) test using IBM ${ }^{\circledR}$ SPSS ${ }^{\circledR}$ Statistics 20 (Armonk, NY, USA). Soil water content contours were created using OriginPro 9.0.0 (OriginLab Corporation, Northampton, MA, USA).

\section{Results}

\subsection{Runoff Yield and Infiltration Processes}

The runoff intensity exhibited an increasing trend with rainfall duration in all treatments. Both sole use and co-use of FA and PAM resulted in obviously higher runoff intensities than the control (Figure 2). At the end of the rainfall event, the sole use of FA (Figure 2a) and PAM (Figure 2b) increased runoff intensity by $94 \%-101 \%$ and $51 \%-55 \%$, respectively, compared with the control. Moreover, the sole use of $15 \%$ FA resulted in consistently higher runoff intensities than the values observed in 10\% FA alone treatment $(p<0.05)$. The sole use of higher rate of PAM also caused some significantly higher runoff intensities compared with the $0.01 \%$ PAM alone treatment during the whole rainfall event $(p<0.05)$. In comparison with the sole use of $10 \%$ and $15 \%$ FA, respectively, the co-use of FA and PAM resulted in consistently higher runoff intensities during the whole rainfall event (Figure 2c,d). Namely at the end of the rainfall event, the co-use of $10 \%$ FA and $0.01 \%-0.02 \%$ PAM increased runoff intensity by $5.3 \%-6.5 \%$ compared with the sole use of $10 \%$ FA (Figure $2 \mathrm{c}$ ), and the co-use of $15 \%$ FA and $0.01 \%-0.02 \%$ PAM increased runoff intensity by $3.4 \%-5.3 \%$ compared with the sole use of $15 \%$ FA (Figure 2d). Despite of some small but significant increases in runoff intensity caused by higher PAM rate combined with $10 \%$ or $15 \%$ FA $(p<0.05)$, the variations in runoff intensity in $10 \%$ FA and $0.01 \%-0.02 \%$ PAM treatments were generally comparable. Likewise, comparable variations in runoff intensity were noted in $15 \%$ FA and $0.01 \%-0.02 \%$ PAM treatments. In addition, the sole use of FA slightly promoted runoff formation compared with the control (Figure 2a), while the sole use of PAM caused a prominent advancement in runoff formation (Figure $2 b$ ). The runoff formation was further promoted by the co-use of FA and PAM with increasing application rates (Figure 2c,d). The initial runoff yield time in different treatments after the rainfall began is listed in Table 1 . The earliest runoff formation was observed in 15\% FA and $0.02 \%$ PAM treatment, which was 8.5 min earlier than the control. Therefore, both FA and PAM increased runoff intensity and promoted runoff formation, and the effect became more obvious when the two additives were applied together.

(a) Different $\mathrm{FA}$ rates and $0 \%$ PAM

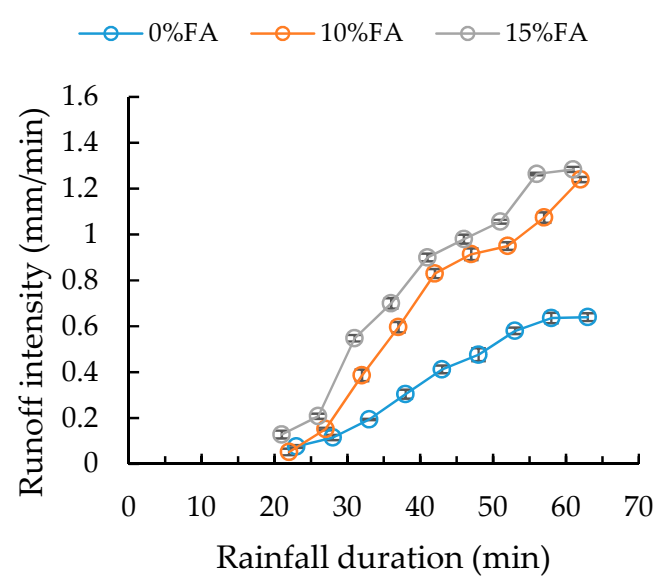

(b) $0 \% \mathrm{FA}$ and different PAM rates

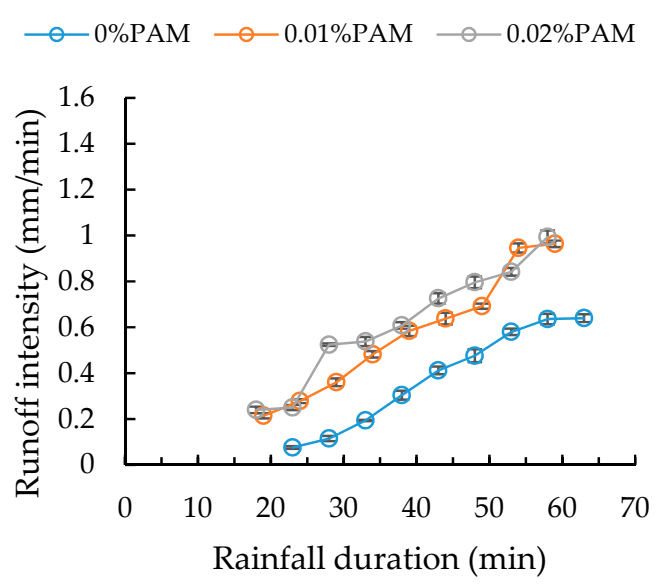

Figure 2. Cont. 
(c) $10 \%$ FA and different PAM rates

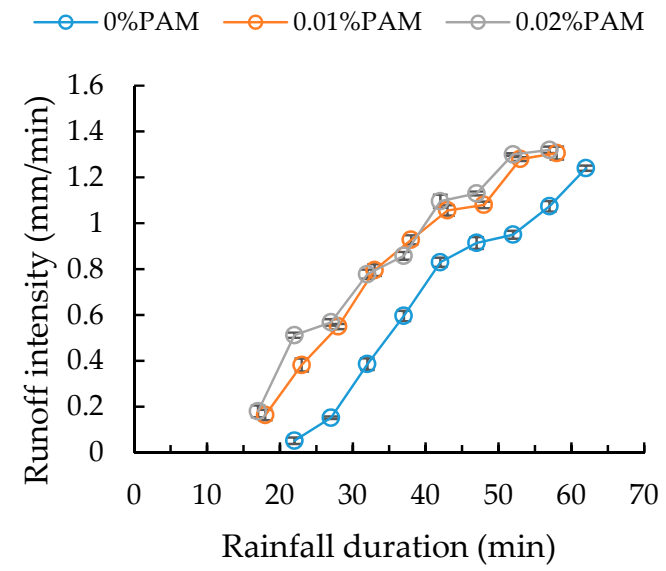

(d) 15\%FA and different PAM rates

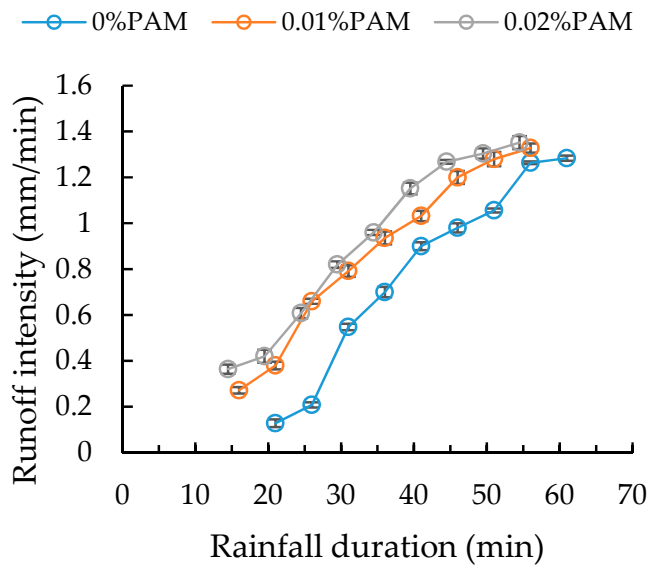

Figure 2. Changes in instantaneous runoff intensity with rainfall duration for different treatments. The error bars represent one standard deviation $(n=3)$.

Table 1. Initial runoff yield time in different treatments.

\begin{tabular}{cc}
\hline Treatment & Initial Runoff Yield Time after Rainfall Began (min) \\
\hline Control (0\% FA and 0\% PAM) & 23 \\
10\% FA and 0\% PAM & 22 \\
15\% FA and 0\% PAM & 21 \\
0\% FA and 0.01\% PAM & 19 \\
0\% FA and 0.02\% PAM & 18 \\
10\% FA and 0.01\% PAM & 18 \\
10\% FA and 0.02\% PAM & 17 \\
15\% FA and $0.01 \%$ PAM & 16 \\
15\% FA and 0.02\% PAM & 14.5 \\
\hline
\end{tabular}

As shown in Figure 3, the cumulative runoff yield increased with increasing FA and PAM rates in all treatments. To be specific, the effect of FA on increasing cumulative runoff yield was less significant than that of PAM at the early stage of the rainfall event (viz. before $50 \mathrm{~min}$ ). However, as the rainfall duration increased (viz. after $50 \mathrm{~min}$ ), the effect of FA on promoting cumulative runoff yield became more prominent than that of PAM. At the end of the rainfall event, the highest cumulative runoff yield was observed in 15\% FA and 0.02\% PAM treatment, which increased by $140 \%$ compared with the control. Moreover, when comparing the cumulative runoff yield for soil treated with FA alone and soil treated with FA and PAM at the end of the rainfall event, it was found that the value increased by $22 \%-26 \%$ in $10 \%$ FA and $0.01 \%-0.02 \%$ PAM treatments than $10 \%$ FA alone treatment and by $11 \%-16 \%$ in $15 \%$ FA and $0.01 \%-0.02 \%$ PAM treatments than $15 \%$ FA alone treatment, respectively. This finding suggests that PAM promoted the effect of FA on increasing runoff intensity for the sandy soil. 


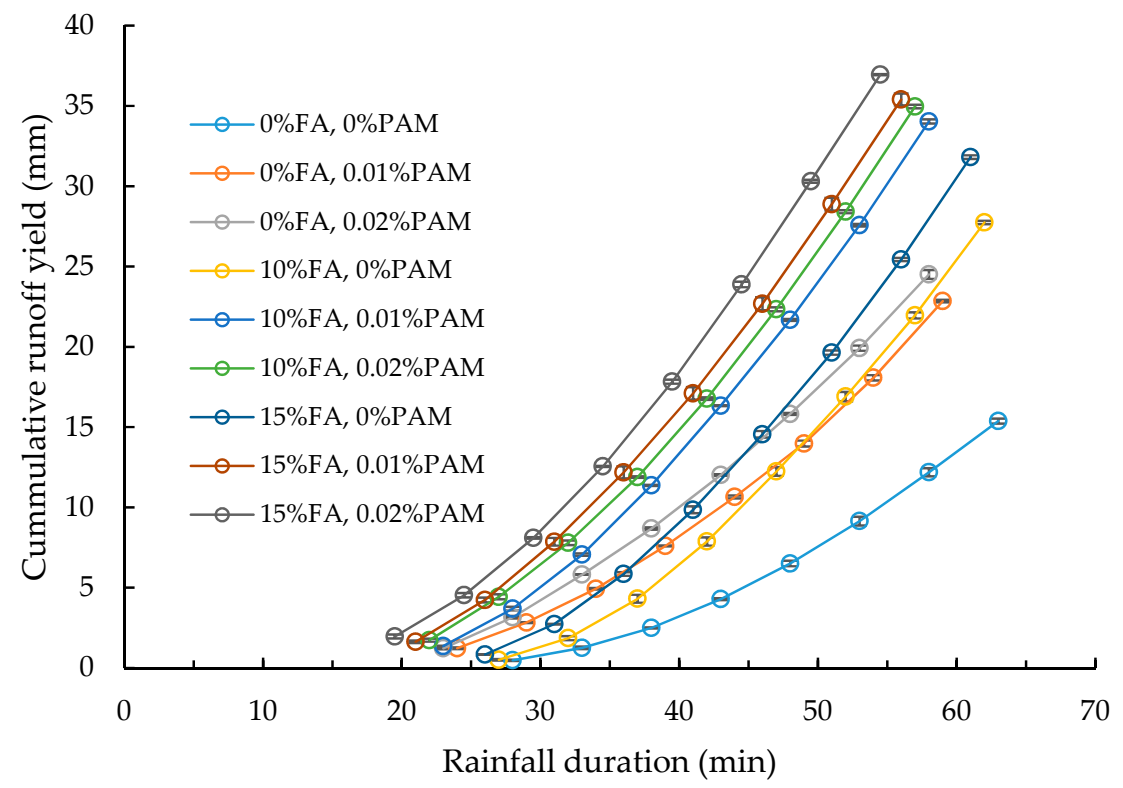

Figure 3. Changes in cumulative runoff yield with rainfall duration for different treatments. The error bars represent one standard deviation $(n=3)$.

As shown in Figure 4, the average infiltration rate for all treatments decreased with increasing rainfall duration. On the contrary to the trend for cumulative runoff yield as affected by FA and PAM, there was a decreasing trend in average infiltration rate with increasing FA and PAM rates. For the sole use of FA and PAM, with increasing rainfall duration, the effect of PAM on reducing average infiltration rate was exceeded by FA. At the end of the rainfall event, the lowest average infiltration rate was observed in 15\% FA and $0.02 \%$ PAM treatment, which decreased by $35 \%$ compared with the control. Moreover, the effect of FA on reducing the average infiltration rate of sandy soil was enhanced by PAM.

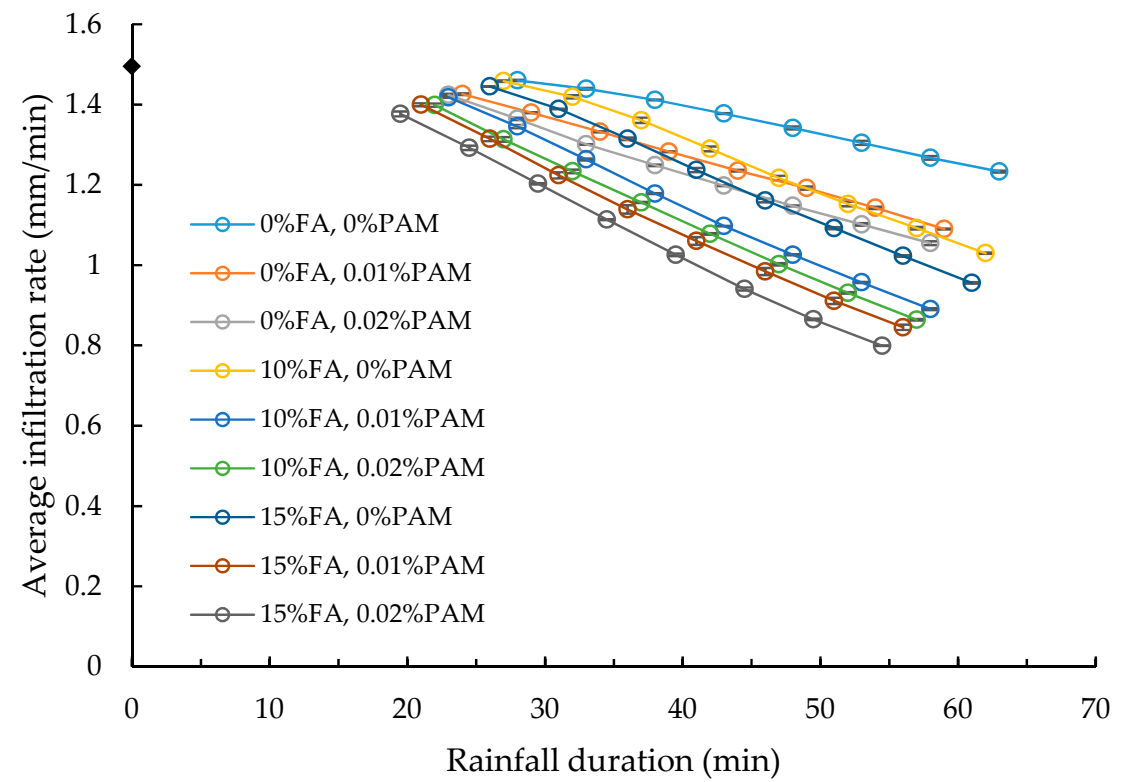

Figure 4. Changes in average infiltration rate with rainfall duration for different treatments. The error bars represent one standard deviation $(n=3)$. The initial infiltration rate (at the time of rainfall began) in all treatments was assumed to be equal to the rainfall intensity, i.e., $1.5 \mathrm{~mm} / \mathrm{min}$, shown as black diamond symbol. 


\subsection{Sediment Yield Process}

The sediment yield rate increased dramatically by FA compared with the control, and the value exhibited an increasing trend with rainfall duration (Figure 5a). At the end of the rainfall event, the sediment yield rate in 10\% FA alone and 15\% FA alone treatments was 28- and 37-times, respectively, higher than the control. The sediment yield rate in PAM alone treatments fluctuated with rainfall duration, and the value decreased with increasing PAM rate (Figure 5b). At the end of the rainfall event, the sediment yield rate decreased by $65 \%$ by $0.01 \%$ PAM and by $74 \%$ by $0.02 \%$ PAM, respectively, compared with the control. Moreover, the effect of PAM alone on sediment yield rate was much less obvious in comparison with that of FA alone. A prominent reduction in sediment yield rate was observed in $10 \%$ FA and $0.01 \%-0.02 \%$ PAM treatments when compared with the sole use of $10 \%$ FA, while the values observed in these two FA and PAM treatments were quite close (Figure $5 \mathrm{c}$ ). The application of $15 \%$ FA and $0.01 \%-0.02 \%$ PAM also reduced sediment yield rate compared with the sole use of $15 \%$ FA, and the value decreased with increasing PAM rate (Figure $5 \mathrm{~d}$ ). Notably, sediment yield rates observed in $15 \%$ FA and $0.01 \%-0.02 \%$ PAM treatments were significantly higher than those in $10 \%$ and $0.01 \%-0.02 \%$ PAM treatments. In addition, the initial sediment yield time in each treatment matched the corresponding initial runoff yield time.

(a) Different FA rates and 0\%PAM

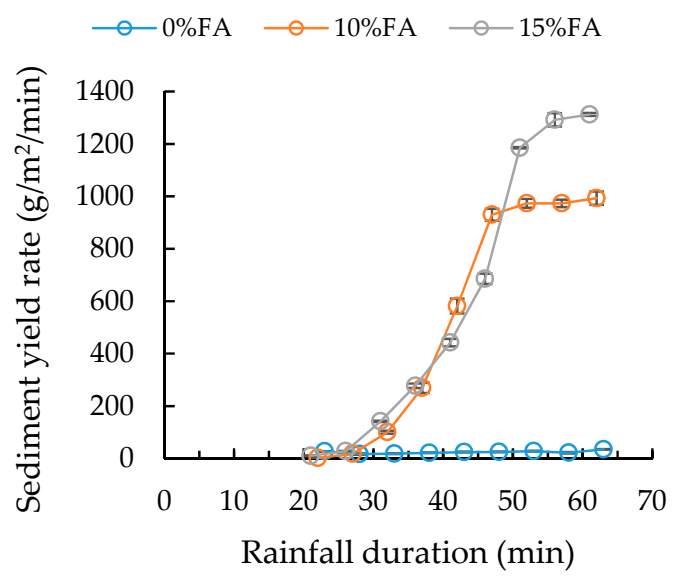

(c) $10 \%$ FA and different PAM rates

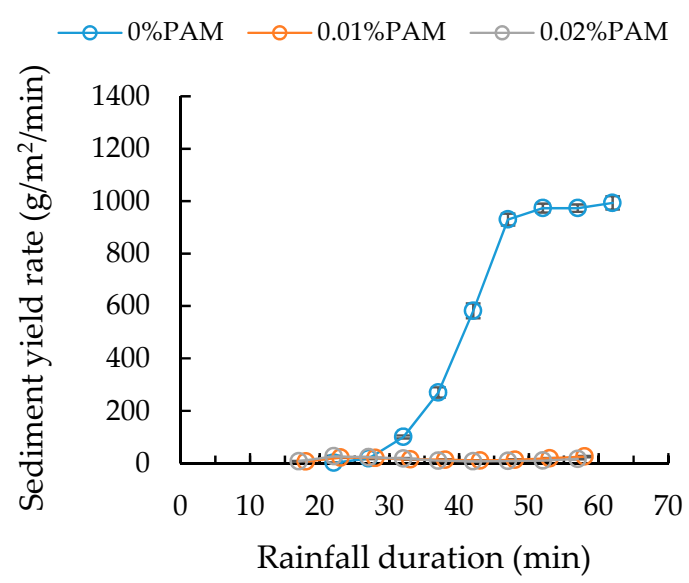

(b) $0 \%$ FA and different PAM rates

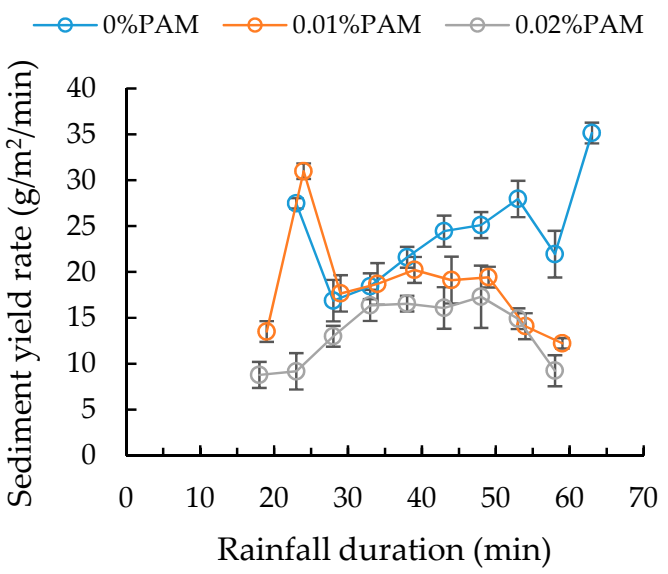

(d) 15\%FA and different PAM rates

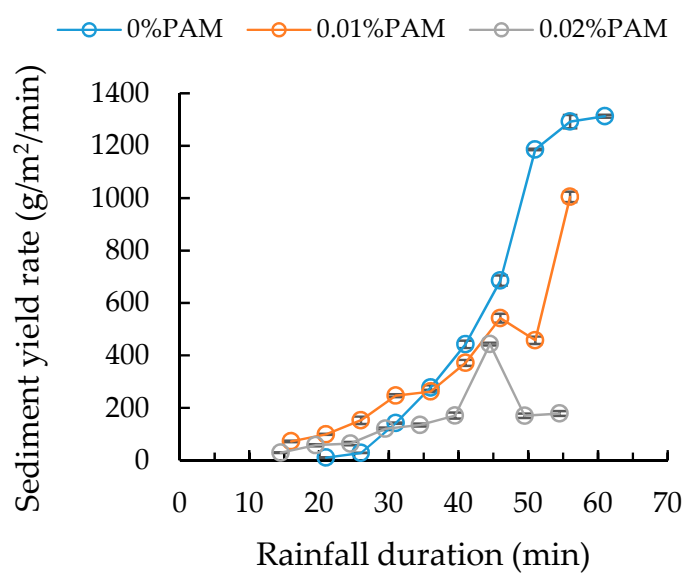

Figure 5. Changes in instantaneous sediment yield rate with rainfall duration for different treatments. The error bars represent one standard deviation $(n=3)$. 
Figure 6 displays changes in cumulative sediment yield with rainfall duration for different treatments. With increasing rainfall duration, there was a very small increase in cumulative sediment yield for the control, soils treated with PAM alone, and soils treated with $10 \%$ FA and $0.01 \%-0.02 \%$ PAM. Moreover, there was no obvious difference in cumulative sediment yield among these treatments $(p<0.05)$. In contrast, the cumulative sediment yield for soils treated with FA alone and soils treated with $15 \%$ FA and $0.01 \%-0.02 \%$ PAM increased prominently with increasing rainfall duration. At the end of the rainfall event, the highest cumulative sediment yield was observed in 15\% FA and 0\% PAM treatment, 25-times higher than the control, followed by 10\% FA and 0\% PAM treatment, 15\% FA and $0.01 \%$ PAM treatment, and $15 \%$ FA and $0.02 \%$ PAM treatment. These findings suggest that the addition of FA weakened the sandy soil antiwater erosion ability, while PAM exhibited a positive effect on the resistance of sandy soil to water erosion. Taking 10\% FA and varying PAM rates as an example (Figure 7), after the rainfall event, obvious interrill erosion was observed in $10 \%$ FA and $0 \%$ PAM treatment, while the soil surface in $10 \%$ FA and $0.01 \%-0.02 \%$ PAM treatments remained relatively intact.

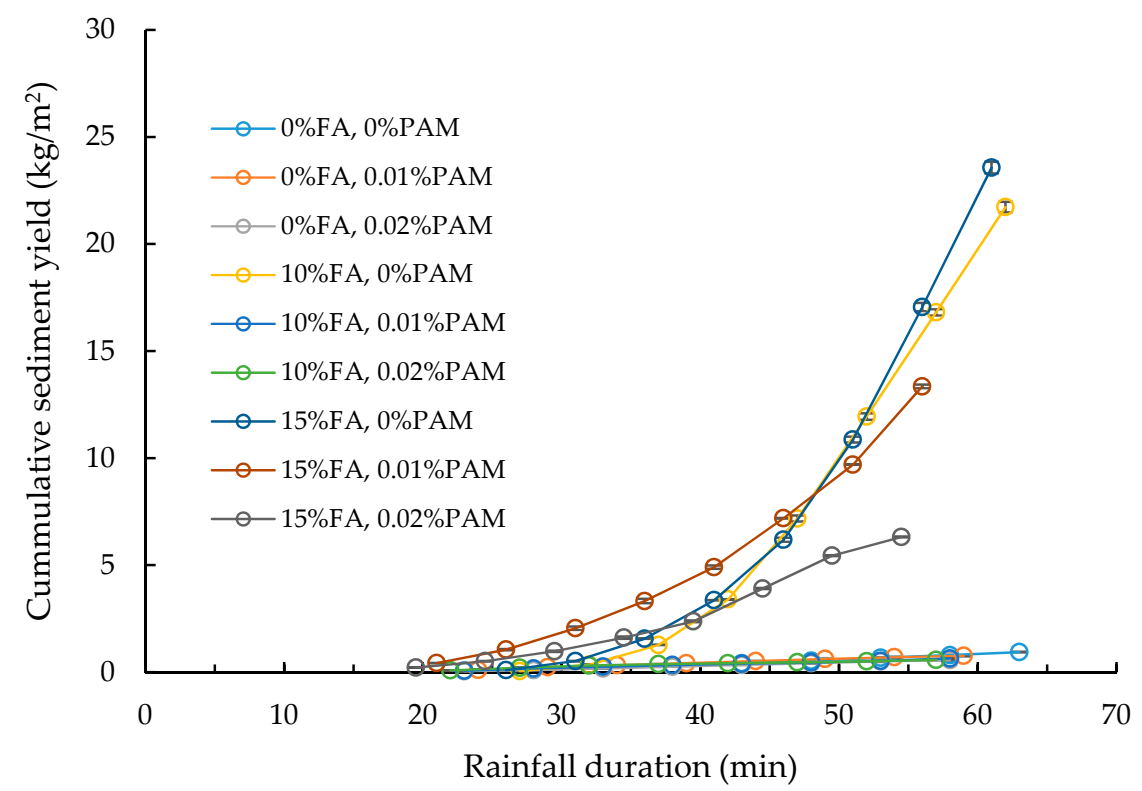

Figure 6. Changes in cumulative sediment yield with rainfall duration for different treatments. The error bars represent one standard deviation $(n=3)$. 


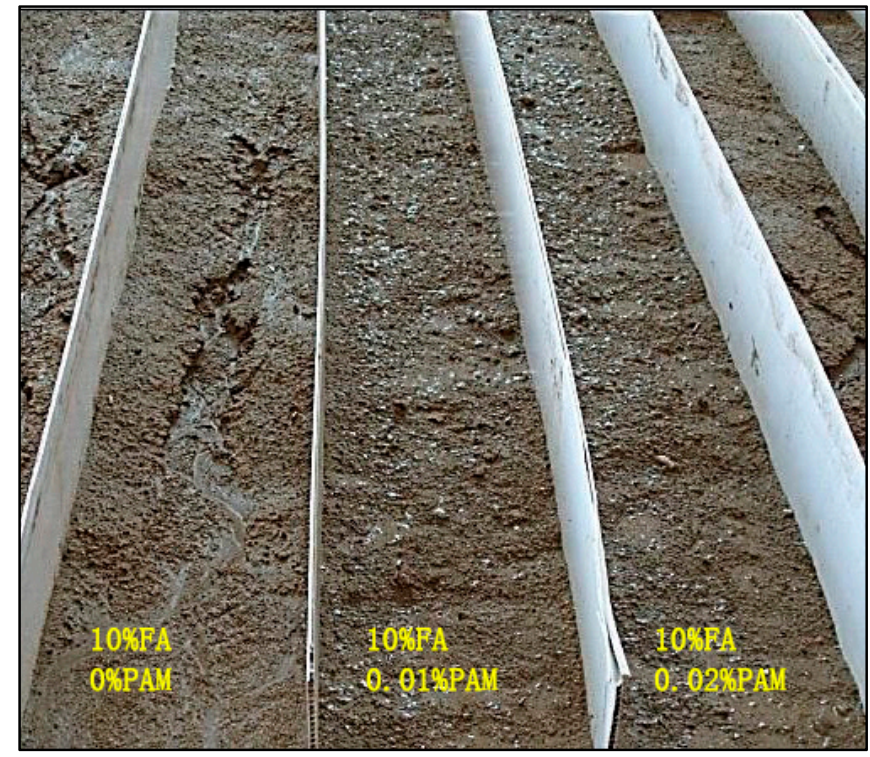

Figure 7. Surface morphology of soil treated with $10 \%$ coal fly ash (FA) and varying polyacrylamide (PAM) rates.

\subsection{Redistribution of Water in Soil Profile}

Figure 8 shows two-dimensional distribution of water content retained in soil profile for different treatments after $4 \mathrm{~h}$ equilibration upon ending the rainfall event. Compared with the control which had a mean water content of $17.4 \%$ (Coefficient variation $(C V)=0.15$ ) (Figure $8 \mathrm{a}$ ), the value increased by $37 \%$ and $43 \%$ by $10 \%$ FA addition and $15 \%$ FA addition, respectively, with a CV value range between 0.05 and 0.07 (Figure $8 d, g$ ). However, there was only a small increase in the mean water content in PAM alone treatment (Figure 8a-c). Namely the mean water content was $17.7 \%(\mathrm{CV}=0.11)$ and $18.1 \%(\mathrm{CV}$ $=0.15$ ) in $0.01 \%$ PAM alone treatment and $0.02 \%$ PAM alone treatment, respectively. The co-use of FA and PAM resulted in a further but small increase in mean water content (range $24.1 \%-25.5 \%$ ) compared with the soil profiles treated with the same FA rate alone (range $23.9 \%-24.8 \%$ ) (Figure $8 \mathrm{~d}-\mathrm{i}$ ). In addition, the variation in spatial distribution of soil water content became less obvious with increasing FA and PAM rates (e.g., Figure 8g-i). Overall, FA exhibited a prominent effect on increasing water content retained in the sandy soil, and PAM further enhanced this effect to a small extent.
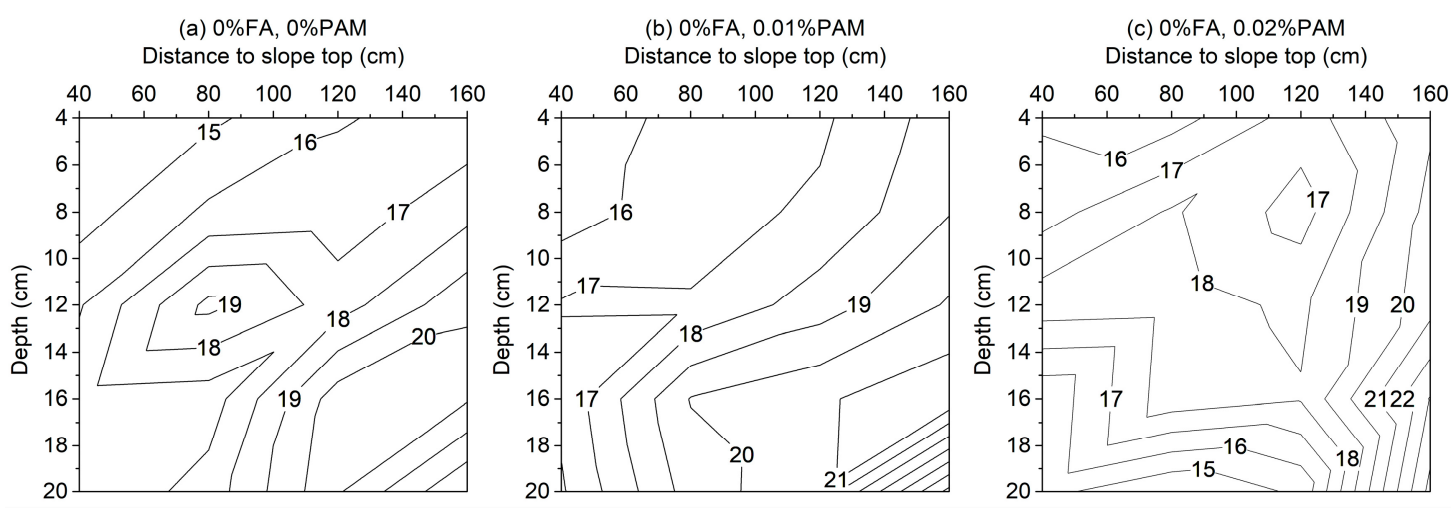

Figure 8. Cont. 


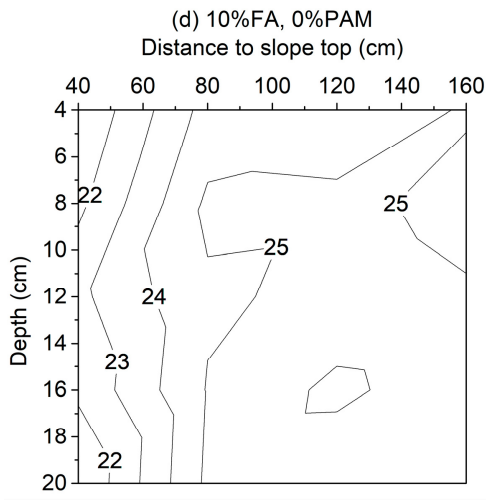

(g) $15 \% \mathrm{FA}, 0 \% \mathrm{PAM}$ Distance to slope top $(\mathrm{cm})$

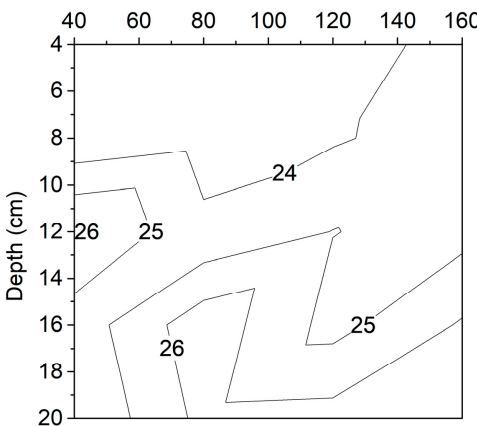

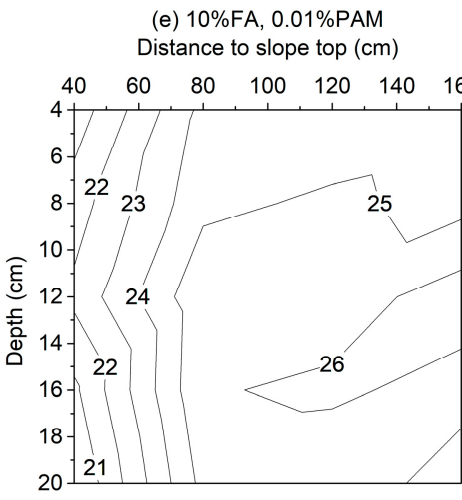

(h) $15 \% \mathrm{FA}, 0.01 \% \mathrm{PAM}$ Distance to slope top $(\mathrm{cm})$

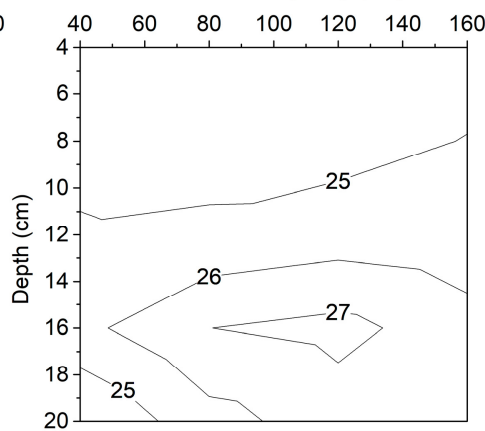

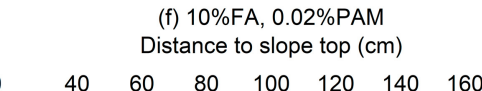

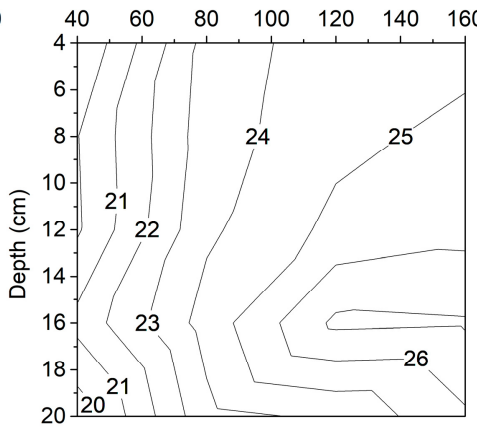

(i) $15 \% \mathrm{FA}, 0.02 \% \mathrm{PAM}$ Distance to slope top $(\mathrm{cm})$

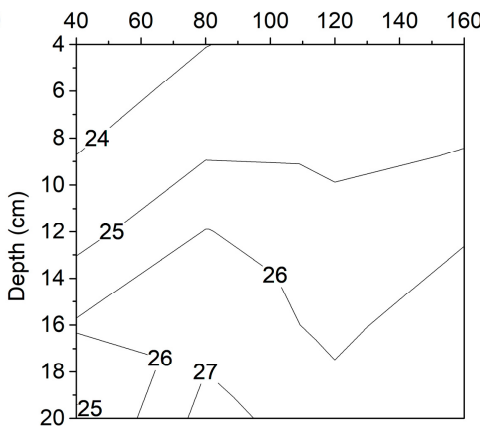

Figure 8. Contour plot showing redistribution of gravimetric water content retained in soil profile for different treatments after rainfall.

\section{Discussion}

FA and PAM increased runoff intensity and cumulative runoff yield, promoted runoff formation, and reduced average infiltration rate of sandy soil. Infiltration capacity is a key soil property determining surface runoff. The role of PAM played in altering soil infiltration rate in this study is different from previous studies $[13,17]$ where PAM was found to increase infiltration rate of coarse-textured soils under rainfall conditions. The difference is probably attributed to the different PAM application protocols:

In the previous studies [13,17], dry granular PAM was spread uniformly on the soil surface prior to rainfall. In this way, PAM could effectively prevent crust formation due to its flocculation function and binding of soil particles, and consequently maintain or increase soil infiltration rate. For example, Tang et al. [13] noted a positive relationship between infiltration rate of loess and PAM coverage rate under simulated rainfall conditions with varying slope gradients and rainfall intensities. The authors [13] ascribed the increased infiltration rate by PAM granules to the inhibitory effect of PAM on rain-induced seal formation. Comparably, some other researchers $[9,10,14]$ observed that PAM applied to soils through irrigation water boosted soil infiltration rate via preventing seal formation under furrow and sprinkler irrigations.

In contrast to spreading PAM granules on soil surface, in this study granular PAM was mixed uniformly with $0-0.2 \mathrm{~m}$ sandy soil or soil and FA mixture. After dissolving in the infiltrating rainfall, the adhesive action of PAM could increase soil liquid viscosity due to its long-chain polymer feature, and therefore reduce soil hydraulic conductivity. In particular, the tendency of PAM to increase viscosity of the infiltrating water can become the dominant phenomenon in sandy soil where there is a lack of particle aggregation [20]. Moreover, viscous PAM solution containing large organic molecules can plug water-conducting pores [20]. As reflected in this study, the effect of PAM on reducing infiltration rate became more significant with increasing PAM rate. This finding agrees with Kang et al. [20] who showed that PAM solution applied to thin clay loam under saturated condition clogged most water-conducting pores smaller than $225-274 \mu \mathrm{m}$ in diameter, and only the large pores $(>255 \mu \mathrm{m})$ 
became available for water and PAM to flow through. Ao et al. [21] mixed PAM granules with sandy soil in a similar laboratory rainfall simulation test as in this study and found that PAM application at lower rates of $0.5-2 \mathrm{~g} / \mathrm{m}^{2}$ reduced stable runoff rate while PAM application rate of $4 \mathrm{~g} / \mathrm{m}^{2}$ increased the runoff amount compared with no PAM application treatment under rainfall intensities of 30,60, and $90 \mathrm{~mm} / \mathrm{h}$, respectively. In addition, the authors [21] noted that the initial runoff formation in 2 and $4 \mathrm{~g} / \mathrm{m}^{2}$ PAM treatments was 3-5 min earlier compared with no PAM application treatment under rainfall intensity of $30 \mathrm{~mm} / \mathrm{h}$. Likewise, the initial runoff formation was advanced markedly by PAM in this study.

Regarding the role of FA played in the infiltration-runoff processes in this study, the reduction in sandy soil infiltration rate is mainly because fine-sized FA particles could fill the pores of the coarse soil particles [28], which would hinder rainfall infiltration. This finding is consistent with Zhao et al. [7] who demonstrated that FA reduced the infiltration rate and saturated hydraulic conductivity of sandy soil by altering the soil texture. Pathan et al. [4] showed that FA-amended sandy soil held a greater volume of irrigation water, and the infiltration rate reduced by $2-8$-fold compared with the unamended soil. The larger volumes of irrigation water held in the FA-amended soil was due to incorporation of fine-sized FA particles which increased total porosity of the soil and shifted pore size distribution from primarily large macropores to many more micropores [6]. Overall, the co-use of FA and PAM resulted in an added effect on increasing runoff and reducing infiltration rate in comparison with the sole use of either additive.

FA increased sediment yield rate dramatically while PAM caused a relatively small reduction in sediment yield rate. Thus, FA and PAM had reversed effects on the resistance of sandy soil to rainfall erosion. Specifically, incorporation of PAM successfully eliminated the negative impact of FA on soil antiwater erosion ability at a lower FA rate of $10 \%$ as indicated by the insignificant difference in cumulative sediment yield between $10 \%$ FA and $0.01 \%-0.02 \%$ PAM treatments and the untreated soil. However, a significant increase in cumulative sediment yield was observed at a higher FA rate of $15 \%$ together with PAM application compared with the untreated soil, suggesting a dominant effect of FA on devastating the soil antiwater erosion ability. It can be therefore inferred that without the adhesive action of PAM, the resistance of FA-amended sandy soil to rainfall erosion was weak. The loose fine-sized FA particles in the soil treated with FA alone might be easily washed away by runoff, resulting in a larger sediment amount than the untreated soil. Whereas, the dissolved PAM in the infiltrating rainfall could bind soil and FA particles in stable aggregates, and consequently improve the antiwater erosion ability of sandy soil amended with FA and PAM. Nevertheless, as shown in this study, excessive FA particles (viz. FA application rate of 15\%) introduced to the soil weakened the adhesive effect of PAM. The effect of PAM on improving soil antierosion ability under simulated rainfall conditions was also observed in Ao et al. [21] where the long chains of PAM were adsorbed on the aggregates of soil surface, binding them together, and increasing their resistance to detachment by runoff.

FA and PAM increased the capacity of sandy soil to storage infiltrating water after the rainfall. To be specific, at the beginning of the rainfall event, the soil infiltration capacity was larger than the rainfall amount, thus all rainfall would penetrate into the soil. As the rainfall duration increased, the topsoil water content increased with increasing infiltrating rainfall quantity meanwhile the infiltration rate decreased. When the soil infiltration rate was lower than the rainfall intensity $(1.5 \mathrm{~mm} / \mathrm{min}$ in this study), water began to accumulate in the soil surface, followed by surface runoff formation and accompanied by possible erosion afterwards. The infiltrating water retained in the soil layer after the rainfall was allowed to redistribute for $4 \mathrm{~h}$ in this study. According to Figure $8,4 \mathrm{~h}$ after the end of the rainfall event, for the untreated soil, there was an increasing trend in soil water content along the slope to the slope foot, meanwhile the soil water content tended to increase first then decrease with increasing depth close to the slope top. This soil water distribution pattern indicated water seepage from the subsoil. In contrast, the soil water distribution pattern became more uniform with increasing FA and PAM rates, indicating hindered migration of water within the soil layer. The increased amount 
of water retained in the amended soil profile was mainly attributed to increased soil capillary porosity and water holding capacity by FA. A similar effect of FA on sandy soil water holding capacity was observed in Pathan et al. [4] and Pathan et al. [6] under in situ irrigation conditions. PAM dissolved by the infiltrating rainfall could also contribute to the hindering of water seepage due to the hydrophilic groups of PAM and viscous colloids formed by PAM [13]. This finding is consistent with Kang et al. [20] who demonstrated that dissolved PAM could be an effective seepage-inhibiting sealant with limited mobility in the soil profile.

\section{Conclusions}

Under the simulated rainfall condition, the infiltration-runoff process in the sandy soil was found to be significantly influenced by FA and anionic PAM, exhibiting an increasing trend in cumulative runoff yield and decreasing trend in average infiltration rate with increasing FA and PAM rates. A higher FA rate resulted in a prominent increase in cumulative sediment yield, whereas PAM tended to prevent the soil surface from being eroded and contributed to improved soil antiwater erosion ability. The water content retained in the soil layer after the rainfall significantly increased by FA and PAM. Overall results suggest that although FA increased infiltrating water storage in sandy soil, when applying FA onto sandy sloping land, synthetic organic polymers such as PAM as demonstrated in this study, can be incorporated to maintain soil antierosion ability. The combined utilization of $10 \%$ FA and $0.01 \%-0.02 \%$ PAM is recommended as optimal for retaining water in the amended sandy soil without devastating the erosion resistance. As vegetation coverage may reduce runoff production and sediment yield, future work can be carried out to investigate the effect of vegetation coverage on hydraulic properties of FA- and PAM-amended sandy soil under rainfall conditions.

Author Contributions: Conceptualization, Z.T. and K.Y.; methodology, Z.T., K.Y., and J.F.; software, K.Y.; validation, K.Y.; formal analysis, K.Y.; investigation, J.F. and K.Y.; resources, Z.T.; data curation, K.Y. and J.F.; writing-original draft preparation, K.Y. and Z.T.; writing—review and editing, K.Y. and Z.T.; visualization, K.Y.; supervision, K.Y. and Z.T.; project administration, Z.T. and K.Y.; funding acquisition, Z.T. and K.Y. All authors have read and agreed to the published version of the manuscript.

Funding: This research was funded by the National Natural Science Foundation of China, grant numbers 41907095 and 51379211, and the Youth Fund of Ministry of Education Laboratory for Earth Surface Processes, Peking University.

Conflicts of Interest: The authors declare no conflict of interest.

\section{References}

1. Salter, P.J.; Williams, J.B. Effects of pulverised fuel ash on the moisture characteristics of soils. Nature 1967, 213, 1157-1158. [CrossRef]

2. Campbell, D.J.; Fox, W.E.; Aitken, R.L.; Bell, L.C. Physical characteristics of sands amended with fly ash. Aust. J. Soil Res. 1983, 21, 147-154. [CrossRef]

3. Adriano, D.C.; Weber, J.T. Influence of fly ash on soil physical properties and turfgrass establishment. J. Environ. Qual. 2001, 30, 596-601. [CrossRef] [PubMed]

4. Pathan, S.M.; Aylmore, L.A.G.; Colmer, T.D. Fly ash amendment of sandy soils to improve water and nutrient use efficiency in turf culture. Int. Turfgrass Soc. Res. J. 2001, 9, 33-39.

5. Pathan, S.M.; Aylmore, L.A.G.; Colmer, T.D. Reduced leaching of nitrate, ammonium, and phosphorus in a sandy soil by fly ash amendment. Aust. J. Soil Res. 2002, 40, 1201-1211. [CrossRef]

6. Pathan, S.M.; Aylmore, L.A.G.; Colmer, T.D. Soil properties and turf growth on a sandy soil amended with fly ash. Plant Soil 2003, 256, 103-114. [CrossRef]

7. Zhao, L.; Tang, Z.; Liu, F. Laboratory tests of fly ash as a sandy soil amendment and its effects on soil water. Acta Sci. Circumstantiae 2009, 29, 1951-1957. (In Chinese with English abstract)

8. Riehl, A.; Elsass, F.; Duplay, J.; Huber, F.; Trautmann, M. Changes in soil properties in a fluvisol (calcaric) amended with coal fly ash. Geoderma 2010, 155, 67-74. [CrossRef]

9. Lentz, R.D.; Sojka, R.E.; Carter, D.L.; Shainberg, I. Preventing irrigation furrow erosion with small applications of polymers. Soil Sci. Soc. Am. J. 1992, 56, 1926-1932. [CrossRef] 
10. Levy, G.J.; Levin, J.; Gal, M.; Ben-Hur, M.; Shainberg, I. Poylmers' effects on infiltration and soil erosion during consecutive simulated sprinkler irrigations. Soil Sci. Soc. Am. J. 1992, 56, 902-907. [CrossRef]

11. Ben-Hur, M. Runoff, erosion, and polymer application in moving-sprinkler irrigation. Soil Sci. 1994, 158, 283-290. [CrossRef]

12. Bjorneberg, D.L.; Westermann, D.T.; Aase, J.K. Nutrient losses in surface irrigation runoff. J. Soil Water Conserv. 2002, 57, 524-529.

13. Tang, Z.; Lei, T.; Zhang, Q.; Zhao, J. Effects of polyacrylamide application on infiltration and soil erosion under simulated rainfalls: I. Infiltration. Acta Pedol. Sin. 2003, 40, 178-185. (In Chinese with English abstract)

14. Santos, F.L.; Reis, J.L.; Martins, O.C.; Castanheira, N.L.; Serralheiro, R.P. Comparative assessment of infiltration, runoff and erosion of sprinkler irrigated soils. Biosyst. Eng. 2003, 86, 355-364. [CrossRef]

15. Tang, Z.; Lei, T.; Yu, J.; Shainberg, I.; Mamedov, A.I.; Ben-Hur, M.; Levy, G.J. Runoff and interrill erosion in sodic soils treated with dry PAM and phosphogypsum. Soil Sci. Soc. Am. J. 2006, 70, 679-690. [CrossRef]

16. Busscher, W.J.; Novak, J.M.; Caesar-TonThat, T.C. Organic matter and polyacrylamide amendment of Norfolk loamy sand. Soil Till. Res. 2007, 93, 171-178. [CrossRef]

17. Wang, H.; Wang, Q.; Shao, M. Laboratory simulation experiment of impact of polyacrylamide on transportation of soil water and nutrients from the loess sloping land. Trans. Chin. Soc. Agric. Eng. 2008, 24, 85-88. (In Chinese with English abstract)

18. Jiang, T.; Teng, L.; Wei, S.; Deng, L.; Luo, Z.; Chen, Y.; Flanagan, D.C. Application of polyacrylamide to reduce phosphorus losses from a Chinese purple soil: A laboratory and field investigation. J. Environ. Manag. 2010, 91, 1437-1445. [CrossRef]

19. Zhao, L.; Tang, Z. Effects of polyacrylamide application on ammonium nitrogen transport to surface runoff and its analytical modeling. Trans. Chin. Soc. Agric. Eng. 2011, 27, 49-54. (In Chinese with English abstract)

20. Kang, J.; McLaughlin, R.A.; Amoozegar, A.; Heitman, J.L.; Duckworth, O.W. Transport of dissolved polyacrylamide through a clay loam soil. Geoderma 2015, 243-244, 108-114. [CrossRef]

21. Ao, C.; Yang, P.; Ren, S.; Xing, W.; Li, X.; Feng, X. Efficacy of granular polyacrylamide on runoff, erosion and nitrogen loss at loess slope under rainfall simulation. Environ. Earth Sci. 2016, 75, 490. [CrossRef]

22. Li, F.H.; Wang, A.P. Interaction effects of polyacrylamide application and slope gradient on potassium and nitrogen losses under simulated rainfall. Catena 2016, 136, 162-174. [CrossRef]

23. Pandey, V.C.; Singh, N. Impact of fly ash incorporation in soil systems. Agr. Ecosyst. Environ. 2010, 136, 16-27. [CrossRef]

24. Shaheen, S.M.; Hooda, P.S.; Tsadilas, C.D. Opportunities and challenges in the use of coal fly ash for soil improvements-A review. J. Environ. Manag. 2014, 145, 249-267. [CrossRef] [PubMed]

25. Yao, Z.T.; Ji, X.S.; Sarker, P.K.; Tang, J.H.; Ge, L.Q.; Xia, M.S.; Xi, T.Q. A comprehensive review on the applications of coal fly ash. Earth-Sci. Rev. 2015, 141, 105-121. [CrossRef]

26. Shainberg, I.; Warrington, D.N.; Rengasamy, P. Water quality and PAM interactions reducing surface sealing. Soil Sci. 1990, 149, 301-307. [CrossRef]

27. Stern, R.; Laker, M.C.; Van der Merwe, A.J. Field studies on effect of soil conditioners and mulch on runoff from kaolinitic and illitic soils. Aust. J. Soil Res. 1991, 29, 249-261. [CrossRef]

28. Yang, K.; Tang, Z. Effectiveness of fly ash and polyacrylamide as a sand-fixing agent for wind erosion control. Water Air Soil Poll. 2012, 223, 4065-4074. [CrossRef]

29. Wang, Y.; Yang, K.; Tang, Z.; Chen, C. The effectiveness of the consolidated desert surface by mixing of fly ash and polyacrylamide in wind erosion control. Water Air Soil Poll. 2016, 227, 429. [CrossRef]

30. Wang, Y.; Yang, K.; Tang, Z. In situ effect of combined utilization of fly ash and polyacrylamide on sand stabilization in North China. Catena 2019, 172, 170-178. [CrossRef]

31. Chinese International Exchange Stations Surface Climate Standard Values Monthly Dataset (1971-2000). Available online: http://data.cma.cn/data/detail/dataCode/SURF_CLI_CHN_MUL_MMON_19712000_CES. html (accessed on 1 October 2019). (In Chinese)

32. Yang, S.; Lin, L.; Li, S.P.; Li, Q.; Wang, X.T.; Sun, L. Assessment and comparison of three high-aluminum fly ash utilization scenarios in Inner Mongolia, China using an eco-efficiency indicator. Waste Manag. Res. 2017, 35, 515-524. [CrossRef] [PubMed] 
33. Ministry of Ecology and Environment of the People's Republic of China. Soil Environmental Quality. In Risk Control Standard for Soil Contamination of Agricultural Land (GB 15618-2018); China Environment Publishing Group: Beijing, China, 2018. (In Chinese)

34. Li, Y. Experimental Study on Transport of Phosphorus and Water in Soil from Sloping Land. Ph.D. Thesis, Northwest A\&F University, Xianyang, China, 2002. (In Chinese with English abstract)

(C) 2020 by the authors. Licensee MDPI, Basel, Switzerland. This article is an open access article distributed under the terms and conditions of the Creative Commons Attribution (CC BY) license (http://creativecommons.org/licenses/by/4.0/). 